\title{
RUPTURE OF THE INTERVENTRICULAR SEPTUM
}

\author{
BY \\ BYRON EVANS AND W. F. ANDERSON \\ From the United Cardiff Hospitals
}

In 1845 Latham recorded the first case of rupture of the interventricular septum following a cardiac infarction. Sager (1934) found only one case in which a diagnosis had been established ante mortem. Fowler and Failey (1948) found fifty-eight reported cases and in seventeen of these a clinical diagnosis had been made; this number has now increased to twenty-three. During 1950 three cases of septal perforation were seen by us and in all the diagnosis was made before death.

\section{Case Reports}

Case 1. A man, aged 61, had been in good health until November, 1949, when he had angina of myocardial ischæmia. Three days later he developed typical symptoms of cardiac infaction. There was no clinical evidence of cardiac enlargement and there were no murmurs. Three weeks later he awoke in the early hours of the morning with severe, sharp and shooting pain in the left breast which continued for two hours. He was short of breath and sweated profusely. On the next day, the apex beat was displaced outwards and a systolic thrill was present in the fourth intercostal space to the left of the sternum. In this area there was a loud, harsh systolic murmur. The diagnosis of perforation of the interventricular septum following cardiac infarction was made.

The cardiogram (Fig. 1) showed inversion of the $T$ wave in lead I with $S-T$ elevation here and in all chest leads (V1 to V7), where deep $Q$ waves were also present. The radiograms (Fig. 2) showed enlargement of the left and right ventricles and hilar congestion.

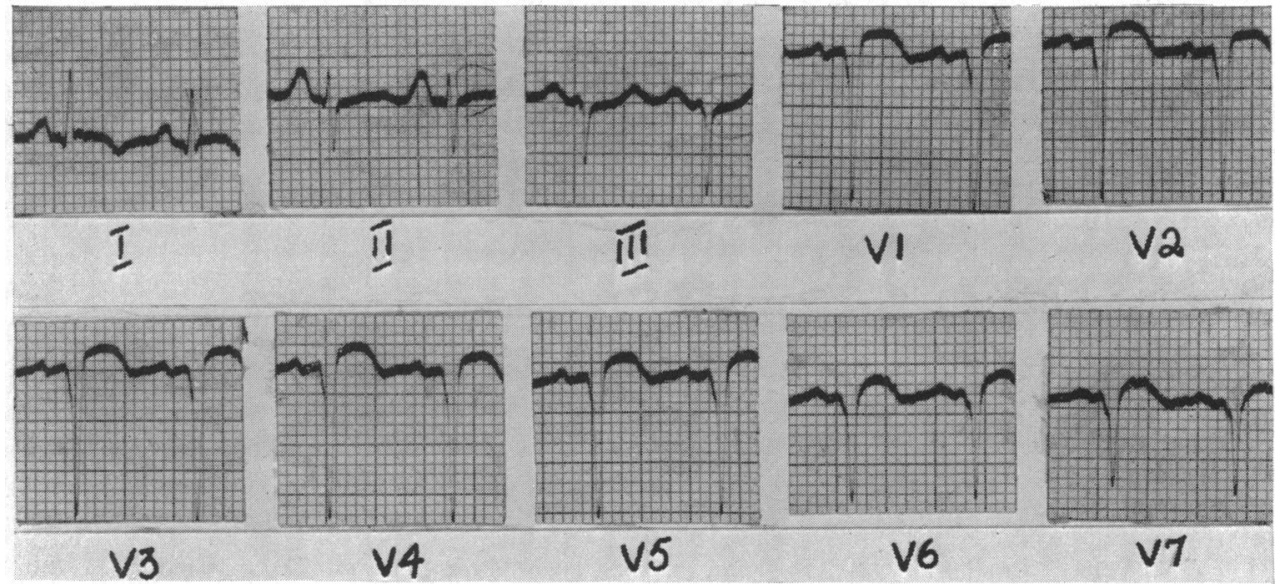

FIG.1-Case $1(27 / 1 / 50)$. S-T elevation and inverted $T$ in $I$; deep $Q$ and $S-T$ elevation in all chest leads.

In October, 1950, he had an attack of severe retrosternal pain of two hours duration, which radiated into the back, the neck and to the shoulders. His condition deteriorated rapidly and he was admitted to hospital. There were obvious signs of heart failure. The pulse was regular and small, the rate was 120 a minute, and the blood pressure could not be recorded. The apex beat was in the anterior axillary line and the systolic thrill was now felt in the mid-clavicular line. The maximum intensity of the loud systolic murmur was one inch external to the midclavicular line in the fifth space. 


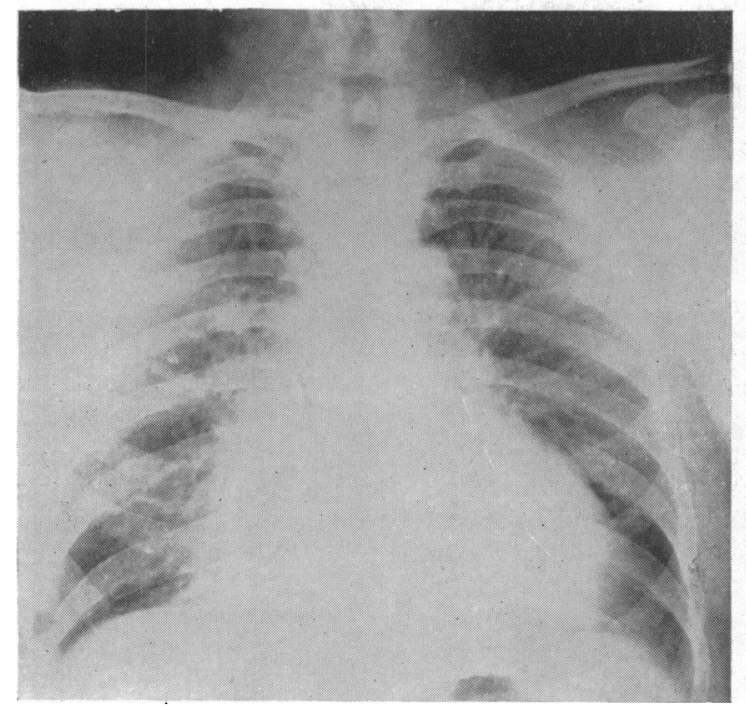

A

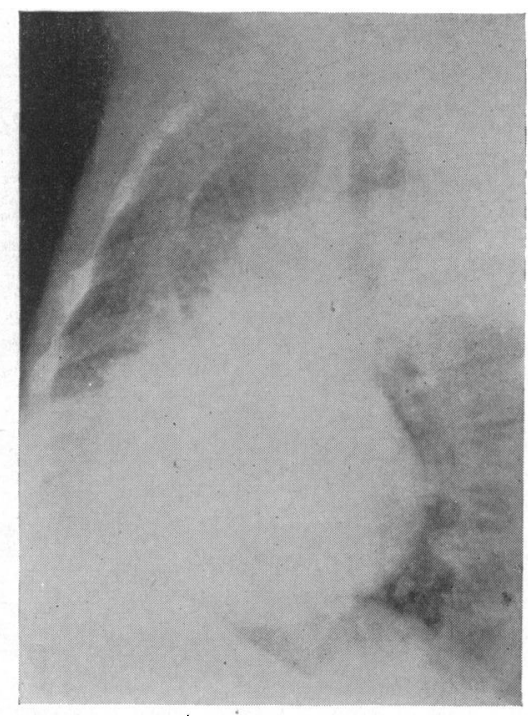

B

FIG. 2-Case 1 (27/1/50). (A) Postero-anterior view. (B) Left oblique view. Enlargement of left and right ventricles. Hilar congestion.

The cardiogram was hardly altered from the first tracing; the deep $Q$ waves, especially in the left ventricular chest leads, remained as the most significant finding; there was no added evidence of right heart preponderance. A radiogram with portable apparatus showed more enlargement of the heart and much pulmonary congestion. The patient died the day after admission, one year after the onset of cardiac pain and approximately eleven months after the rupture of the interventricular septum.

Necropsy (Dr. D. B. Richards). The heart weighed $520 \mathrm{~g}$. Both ventricles were hypertrophied (right, $0.9-1.0 \mathrm{~cm}$. thick; left, $1.7-1.9 \mathrm{~cm}$.). The left ventricle showed a healed infarct involving the lower halves of the anterior wall and septum. The ventricular wall in the infarcted area was thin and fibrotic $(2-3 \mathrm{~mm}$. thick) and covered by laminated thrombus. At the posterior part of the septum, at the edge of the infarct, was an interventricular communication, crescentic in shape and measuring $0.5 \mathrm{~cm}$. along vertical axis and $0.25 \mathrm{~cm}$. wide. The endocardium around the defect on the right side of the septum was thickened and opaque. The left coronary artery showed marked atheroma with foci of calcification and soft pultaceous areas; the vessel was occluded $2.5 \mathrm{~cm}$. from the origin of the left descending branch for a distance of $3 \mathrm{~cm}$. by organized thrombus. The right coronary artery showed severe atheroma and was occluded $2.5 \mathrm{~cm}$. from its origin by recent red thrombus, which extended for $3.5 \mathrm{~cm}$.

Case 2. A man, aged 57, was admitted to the hospital on September 1, 1950. His health had been good until 16 days before, when he had severe and persistent retrosternal pain. When seen two hours later he was grey in colour and the skin was cold and moist. The heart sounds were distant and there were no murmurs. He made good progress until four days before admission when he suddenly awoke with epigastric pain radiating to the upper chest. When seen in hospital the pulse was barely perceptible and the blood pressure could not be recorded. The heart rate was 120 a minute. The apex beat was displaced one inch beyond the midclavicular line. There was no thrill. A loud blowing systolic murmur was heard all over the præcordium with its maximum intensity in the fourth interspace at the left sternal border. Signs of heart failure were present. A clinical diagnosis of rupture of the interventricular septum following a cardiac infarction was made.

The cardiograms initially showed auricular tachycardia with 3 to 1 (as a rule) A-V block, and later sinus rhythm, with inverted T waves in lead II and III. Radiograms with portable apparatus showed enlargement of right and left ventricles, pulmonary congestion, and bilateral pleural effusions.

Signs of heart failure increased and he died on October 29,63 days after the rupture of the septum.

Necropsy (Dr. D. B. Richards). The heart weighed $420 \mathrm{~g}$. and was enlarged from dilatation of right ventricle (muscle, $0.4-0.5 \mathrm{~cm}$. thick) and hypertrophy of the left (muscle, 1.6-1.7 cm. thick). There was a large globular thrombus in the right auricular appendage and an oval thrombus $2 \times 1.5 \times 1.5 \mathrm{~cm}$. adherent to the margin of the coronary sinus. A healed infarct involved the upper two-thirds of the posterior part of the septum and posterior wall of the left ventricle; its upper border extended to within $1.5 \mathrm{~cm}$. of the mitral ring. The ventricular wall at the site of infarction was 2 to $3 \mathrm{~mm}$. thick and covered in its upper part 
by pale laminated thrombus; in its lower part there was an interventricular communication measuring $1.5 \mathrm{~cm}$. in its vertical axis and $0.8 \mathrm{~cm}$. wide (Fig. 3). The endocardium on the right side of the septum was opaque and thickened for a distance of $1 \mathrm{~cm}$. around the perforation. Both coronary arteries showed severe atheroma with numerous yellow crescentic plaques reducing the lumen to a mere slit-like space in areas. The right coronary, $2 \mathrm{~cm}$. from its origin, was occluded for a distance of $1 \mathrm{~cm}$. by an organized thrombus. The aorta showed severe atheroma and ulceration.

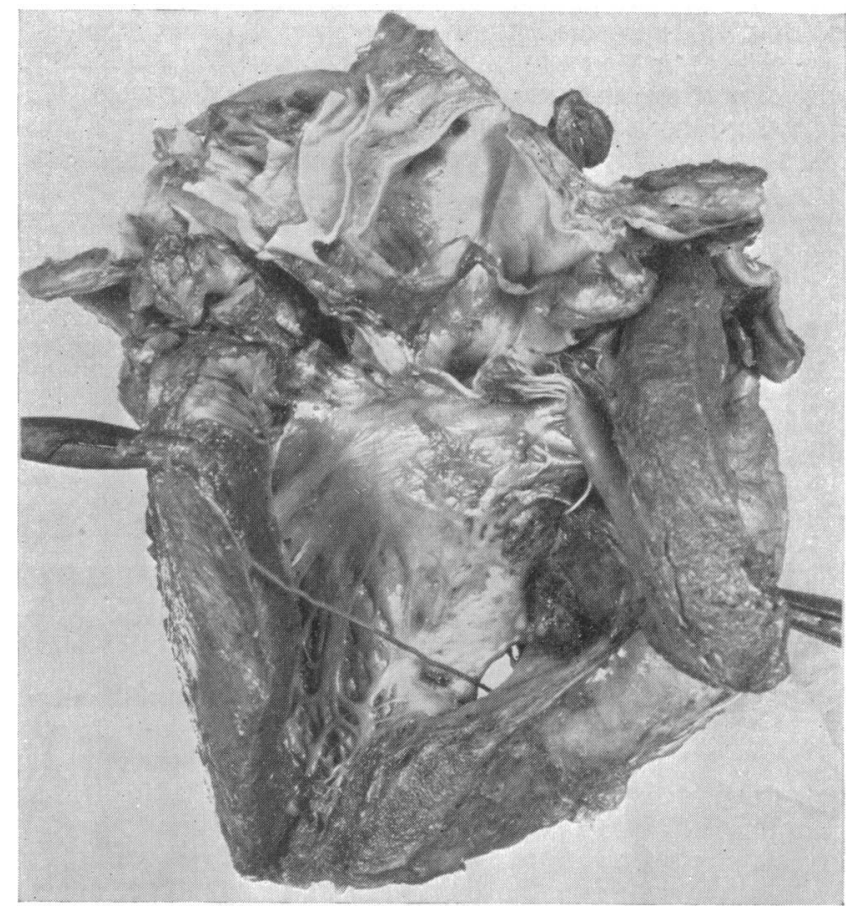

Fig. 3-Case 2. Left ventricular aspect. Infarct of septum with probe in large perforation.

Case 3. A man, aged 63, was admitted to the hospital in May, 1950. He had been well until ten days beforehand, when he complained of continuous pain in the front of the chest; but he was still able to carry on with his work. When seen, there were no cardiac murmurs. On the day he was admitted to the hospital he awoke with severe retrosternal pain and was very breathless. He was orthopnoic, apprehensive and his skin was pale and moist. His pulse rate was $100 \mathrm{a}$ minute and regular in rhythm. The blood pressure was $90 / 75$. The apex beat was faintly felt $11 \mathrm{~cm}$. from the midline in the fourth left interspace. A systolic thrill was present to the left of the lower end of the sternum extending outwairds to the apex. A harsh loud systolic murmur was heard all over the præcordium, and was loudest in the fourth interspace to the left of the sternum and at the apex.

The cardiogram showed prominent $Q$ waves and $\mathbf{S}-\mathbf{T}$ elevation in the limb leads and in CR1 and CR4.

He developed signs of heart failure. On the day after admission a pericardial rub was heard all over the sternum. Radiological examination of the chest showed a marked increase in the size of both sides of the heart with congestion at the lung bases. He died 14 days after the rupture of the interventricular septum.

Necropsy (Dr. A. G. Heppleston). The heart weighed $450 \mathrm{~g}$. There was a fairly recent infarct involving the anterior part of the left ventricle and interventricular septum. The left ventricle was dilated. There was a perforation $0.5 \times 0.5 \mathrm{~cm}$. in the lower end of the interventricular septum. The pericardium showed fibrinous pericarditis with early organization. The valves were normal. There was thrombosis on the endocardium over the infarct. The coronary arteries were atheromatous; this was severe in the left descending branch which showed a recanalized thrombus. The aorta was atheromatous.

\section{Discussion}

Our three patients gave a history of recent cardiac infarction. At the start of the illness cardiac murmurs were not heard. Subsequently they complained of sudden severe pain in the epigastrium or in the chest accompanied by breathlessness. In these cases the clinical diagnosis of rupture of the interventricular 
septum was made from the appearance of a harsh systolic mumur, perhaps with a systolic thrill, in the fourth or fifth interspace near the left border of the sternum. In our series the rupture was relatively small in Cases 1 and 3 and in these a thrill was palpable, but in case 2 only a systolic murmur was heard, where a large septal perforation was present. Reviewing the recorded cases it would seem that a systolic thrill is present if the perforation is small. ${ }^{-}$The characteristic systolic murmur of an interventricular septal defect is usually situated in the fourth interspace near the left border of the sternum, but it is interesting to note that in Case 1 the thrill and the site of the maximum intensity of the murmur were gradually displaced laterally during the long period of observation. In accord with previous reports, all our patient's developed signs of heart failure immediately or very soon after the perforation of the septum. The clinical features of perforation of interventricular septum are almost identical in all the reported cases, but up to 1950 there have been three cases in which no murmurs have been noted and in these a clinical diagnosis was impossible. The only condition in any patient known to have had a cardiac infarction likely to be confused with septal perforation is rupture of a papillary muscle; this is even less common, the murmurs are louder, may be systolic and diastolic in time and nearer the apex of the heart. Cardiac failure is predominantly left sided.

It has been stated (MacWilliam, 1923) that the blood pressure can, under certain circumstances, be increased during sleep and this may explain the occurrence of the septal rupture during the night in our three cases. Disturbance of intraventricular conduction is very rarely found in cases of acquired septal perforation, and was not demonstrated in the electrocardiograms of our patients. Nareff et al. (1950) state that only three cases have been reported in which this defect of conduction has been noted. The rarity of this abnormality can be explained by the position of the perforation which is usually near the apex of the heart and this is shown in our specimens.

It is known that the interventricular septum is richly supplied by blood vessels and the infrequency of its rupture has been attributed to this adequate anastomosis. When perforation occurs there is usually severe and diffuse atheroma of the coronary arteries. In each of our patients, both coronary arteries were very atheromatous or actually occluded by a thrombus. Infarction of the septum is more often associated with infarction of the anterior wall of the left ventricle as in Cases 1 and 3 but less frequently, it is an extension of a lesion of the posterior wall as in Case 2.

In most of the recorded instances septal rupture has occurred within the first fortnight after the cardiac infarction and usually within the first week. In our patient's perforation of the septum took place after an interval of twenty-one days, twelve days and nine days respectively. Sager (1934) found that all those he reviewed died within ten days and Nareff et al. (1950) stated that, of all the reported cases, only seven lived for more than a month after the perforation. Wood and Livezey (1942) reported one patient who survived for four years and ten months, and it is noted that in this instance the interval between infarction and septal perforation was five weeks. One of our patients (Case 1) lived for eleven months and another (Case 2) for sixty-three days. In our experience it would seem that the longer the interval between the cardiac infarction and the occurrence of the rupture, the longer the duration of life after the septal perforation.

\section{Conclusion}

Three examples of perforation of the interventricular septum following a recent cardiac infarct are described and in all a diagnosis was made during life. The clinical and pathological features are discussed.

Perforation of the septum usually occurs within a fortnight of the initial cardiac infarction. Heart failure then develops and death usually ensues in less than one month from the septal perforation. One of our patients survived for eleven months.

We wish to thank Professor A. M. Kennedy for permission to publish Case 3, and Professor J. Gough for access to the necropsy records. We are indebted to Dr. William Evans for his helpful criticism and advice.

\section{REFERENCES}

Fowler, N. O., and Failey, R. B. (1948). Amer. J. med. Sci., 215, 534.

Latham, P. M. (1845). Lectures on Subjects connected with Clinical Medicine comprising Diseases of the Heart. Longmans, Brown; Green and Longmans, London, 2, 168.

MacWilliam, J. A. (1923). Brit. med. J., 2, 1196.

Nareff, M. J., Sklar, L. J., Kelly, F. T., and Reuling, J. R. (1950). New Engl. J. Med., 243, 431.

Sager, R. V. (1934). Arch. intern. Med., 53, 140.

Wood, F. C., and Livezey, M. M. (1942). Amer. Heart J., 24, 807. 